\title{
Chemical structure and preservation processes of organic matter in soils and sediments
}

Until recently, geochemists and soil scientists appeared to belong to two distinct scientific communities that did not interact. However, as recently stressed in a review by Hedges and Oades (Organic Geochemistry, 27, 319-361, 1997), striking similarities exist between soils and surface marine sediments since both environments comprise complex mixtures of degraded biomass containing mineral particles, water and microorganisms. Consequently, a common analytical approach could be developed to examine the chemical structure of both types of organic matter (OM). Spectroscopic and pyrolytic methods are a priori suitable tools but mineral removal is often a prerequisite and may lead to the alteration of the organic matter. Sedimentary OM is usually processed using solvent extractions and base and acid hydrolyses to afford different fractions which are further analysed by conventional methods such as GC and GC/MS, whereas analyses of soil OM usually involves particle size fractionation as a first step. Moreover, observations using light and electron microscopy are increasingly carried out on both types of OM.

Similar preservation processes can be invoked for both environments. Indeed, OM preservation via mineral protection has been considered for a long time in soil science, whereas it has only recently been shown to occur in recent and ancient sediments: the opposite is noted for the selective preservation pathway. It thus appeared to be of interest to the Guest Editors to bring together scientists from both fields of studies in a symposium dealing with the chemical structure and preservation processes in both environments. This was achieved with the organization of a symposium at the 217th Annual Meeting of the American Chemical Society which was held at Anaheim, 21-25 March 1999, under the auspices of the Division of Geochemistry. We wish to thank Bill Casey, chairman of the division, for his help in the organization of this meeting (three half days), which was attended by up to 120 persons, and to the 25 speakers who made this symposium a success. We are also indebted to the Petroleum Research Fund for financial support to the invited speakers (grant 34197-
SE). Finally, we thank the Editors-in-Chief of Organic Geochemistry for giving us this opportunity to have these papers published.

The talks, as the papers in this issue indicate, were divided amongst the following topics: new advances in analytical developments, chemical structure of organic matter, processes of organic matter preservation and the role of the mineral phase for organic matter stabilization.

Kögel-Knabner, in a review of the analytical tools recently used to characterize soil organic matter, emphasizes the importance of combining spectroscopic techniques with thermolytic and chemolytic methods. Laser desorption mass spectrometry was recently used in the characterization of fulvic acids and Brown and Rice show the effect of desorption conditions on the molecular weight distributions thus obtained. Greenwood et al. develop a promising tool, laser micropyrolysis GC-MS, which allows for the direct analysis of petrographically recognizable entities. Isotopes are known to be powerful tools for determining the origin of organic matter. In this respect, Kracht and Gleixner, using a coupled Py-GC/MS-IRMS system, concluded that the dissolved organic matter in a bog lake did not simply result from the dissolution of the bog peat. Using ${ }^{13} \mathrm{C}$ NMR and carbohydrate analysis, the chemical structure of the refractory fraction of an arable soil was investigated by Kiem et al.

Among the various reasons for the stability of organic matter in soils is the occurrence of black carbon; this was considered in anthropogenic soils from the Brazilian Amazon region. Glaser et al. show that different mechanisms are involved in black carbon stabilization depending on the density fraction considered. By combining NMR spectroscopy, thermochemolysis and pyrolysis, Zang et al. bring evidence to support the role of the encapsulation mechanism in the preservation of proteinaceous nitrogen in refractory organic matter. The role of the mineral phase in organic matter preservation is increasingly considered both in soils and sediments. Baldock and Skjemstad describe the mechanisms provided by soil minerals in organic matter 
preservation and Klaiser and Guggenberger investigate the role of dissolved organic matter sorption to mineral surfaces in the preservation of organic matter in soils. Schmidt et al. using particle size separation and ${ }^{13} \mathrm{C}$ NMR show that aromatic structures and polysaccharides can be stabilized by organo-mineral associations. In aquatic sediments, examination of clayorganic matter aggregates by high resolution transmission electron microscopy and electron energy loss spectroscopy reveals intimate associations which led Furukawa to point to a likely effect on the reactivity of organic matter during early diagenesis.

S. Derenne E-mail address: sderenne@ext.jussieu.fr

H. Knicker E-mail address: knicker@pollux.edv.agrar.tu-meunchen.de 